\title{
Decomposing total factor productivity growth in small and medium enterprises, SMEs
}

\author{
Nordin Haji Mohamad ${ }^{1}$ and Fatimah Said ${ }^{2}$ \\ ${ }^{1}$ Institute of Mathematical Sciences, University of Malaya, 50603 Kuala Lumpur, Malaysia \\ ${ }^{2}$ Faculty of Economics and Administration, University of Malaya, 50603 Kuala Lumpur, Malaysia. \\ nordinhm@um.edu.my ${ }^{1}$, fatimahs@um.edu.my ${ }^{2}$
}

\begin{abstract}
Small and Medium Enterprises (SMEs) are one of the principal driving forces in economic development and are the backbones of most economies, developing as well as developed. The purpose of this paper is to model and investigate the total factor productivity growth of SMEs with reference to technological and technical efficiency change which are synonym to adoption and adaptation of technology. To do this, we utilize the linear programming based operations research technique known as Data Envelopment Analysis methodology of Malmquist Total Factor Productivity, TFP index. TFP measures the overall efficiency with which products are produced due to non-physical change. Improvement in TFP will enable the economy to generate a larger output from the same available resources, and hence shifting it to a higher frontier. The technological change component of productivity growth provides a measure of innovation or adoption of new technology and captures shifts in the frontier technology. Technical inefficiency, on the other hand, is measured by the difference between the frontier output and the realized output. Thus decomposition of TFP growth into technical efficiency improvement (adaptation or catching up) and technological change is therefore useful in distinguishing innovation or adoption of new technology by 'best practice' firms from the diffusion of technology. The study utilizes data on SMEs from 42 selected economies (29 European Union and 13 APEC countries) for the period 2004-2008. Results obtained are analyzed and discussed, and some policy implications are suggested.
\end{abstract}

Keywords: Data envelopment analysis, Malmquist total factor productivity, Technical efficiency, Technological change, Small and medium enterprises.

\section{Introduction}

Performance usually involves the evaluating and analysis of productivity. Performance measurement is used to provide information to decision makers, to measure strategies and ensure that they remain effective and to measure continuous improvement (Shackleton, 2007). The indicators are generally quantitative or numerical in values. There exists a number of methodology or techniques for assessing performance via productivity analysis. This includes score card (Banker et al., 2004; Azar et al., 2011), economic production function framework (Hossain \& Al-Amri, 2010), econometric stochastic frontier analysis, SFA (Bhandari \& Maiti, 2007), the analytic hierarchy process (Chakraborty et al.,2011) and data envelopment analysis, DEA Malmquist productivity index (Mohamad \& Said, 2010b).

Of the methodologies, SFA and DEA Malmquist have gained considerable attention in the literature. The former is a parametric approach that requires the specification of a production function and does take statistical noise into account while DEA is a non-parametric approach that requires no functional specification and does not accommodate statistical noise. There is no consensus as to which is the most appropriate technique each has its own strengths and weaknesses (Coli et al., 2007). In this study, we employ the method of DEA Malmquist to measure productivity changes and decompose the total factor productivity, TPF growth into its associated components.

Apart from its use for assessing industrial performance, DEA has been applied in agriculture
Sci.Technol.Edu.

CIndian Society for Education and Environment (iSee)

(Hasanov \& Nomman, 2011), banking (Mostafa,2007), business (Mohamad \& Said, 2010a), education and higher learning (Kao \& Hung, 2008), ecological and environmental studies (Ardabili et al,2007), hospitals and health centres (Laine et al.,2005), manufacturing and industry (Mohamad \& Said, 2010b), nations and regional studies (Mohamad \& Said, 2011b), port management (Wanke et al.,2011), public sectors (Afonso \& Fernandes,2006), services (Barros \& Dieke,2008) and transports (Boame, 2004). Emrouznejad et al. (2008) and Tavares (2002) provided a comprehensive bibliography of methodological and application aspects of DEA.

DEA was employed by Chen and Lu (2006) to measure innovation and managerial performance of 16 companies in Taiwan's IC design industry for the period 2001-2003. Three inputs viz. number of employees, general and administrative expenditures and R\&D expenditure and four outputs viz. net sales, number of patents, patent citation and market value were selected to characterize the parameters in the multiple-stage analysis. Results show that eight firms are operating at an optimal scale. The average scores of productive efficiency is 0.854 , of pure technical efficiency is 0.902 and the scale efficiency is 0.945 . However, some companies were found to confront the dilemma of growth or managerial efficiency which indicated that not all innovative efforts may result in financial boosts.

Yang (2006) utilizes DEA methodology to examine the technical efficiency, the production index and input resources of SMEs in Korea during 2000-2002. Comparison was made on the efficiency of enterprises

"Small and Medium enterprises" http://www.indjst.org
N.H.Mohamad \& F.Said Indian J.Sci.Technol. 
located in the capital region and non-capital region so as to induce the political significance of regional perspective and to analyze the benefits and disadvantages of the capital reallocation policy in Korea. Large scale enterprises in heavy and chemical industry showed more efficient production than small-scale enterprises. However, the total factor productivity of SMEs is improving as compared to large-sized enterprises. Also, enterprises located in capital area show greater efficiency than those in non-capital regions implying that proper distribution of equity in the political operation of Korea is desired.

In another study, Radam et al. (2008) determines the technical efficiency of 7360 SMEs in Malaysia for the year 2004 using Cobb-Douglas stochastic frontier production model. Results show that only 3.06 percent of the total firms are considered technically efficient. Technical inefficiency varies from 0.30 to 97.10 percent. The focus should therefore be on efficiency improvements and lean production in order to sustain operations and growth. Thus, policy makers should play significant roles in formulating adequate policies and programs to assist SMEs to develop their managerial and technical skills especially in creating innovations and generating economic value from knowledge. The stochastic frontier production model was also utilized by Shazali et al., (2004) to examine the technical efficiency of Malaysian furniture industry. They found that actual firm's output is 20 percent less than maximal output which can be achieved from the existing level of inputs.

Ten indicators were used to measure the level of innovativeness of fifty Peninsula Malaysia-based manufacturing SMEs in a study conducted by Yahya et al., (2011). Following Laforet and Tann (2006) the top 20 percent companies which scored high on the ten criteria were compared with the bottom 80 percent companies which scored low on the same criteria. The former were referred to as 'more innovative' companies while the latter were referred to as 'less innovative' companies. It is found that none of the company surveyed was consistently innovative over the ten indicators. Among the findings are one of the drivers of innovation in small manufacturing firms is process innovation including leadership factor and culture, while the main drawbacks are lack of knowledge and skills, networking and training due to lack of financial resources. In less innovative SMEs, training is perceived to be not important as compared to more innovative companies which perceived it to be of high importance.

Another study focusing on SMEs in the Malaysian manufacturing sector investigates the relationship of internationalization and performance (Chelliah et al., 2010). Data was collected from a sample of 77 SMEs in the northern region of Peninsular Malaysia. Internationalization refers to market liberalization and digitization to encourage large corporations and the SMEs to operate beyond their national borders and
Vol. 5 No. 5 (May 2012)

ISSN: 0974- 6846 compete with each other in foreign countries and new regions (Barkema et al., 2002). The financial performance utilized in the study is measured in terms of the average sales growth, the average rate of profit or return on sales (ROS) and the staff turnover rate. These performance indicators are formulated into an index of performance. The study convincingly demonstrates that there exists a positive relationship between internationalization and performance. Internationalization can improve performance and motivate firms to continuously capture foreign markets. It shows that SMEs can increase their return on sales by taking their current products into foreign markets either on their own or through foreign alliances.

In this study, we conduct the performance evaluation and assessment of the dynamic adaptation and adoption or innovation in SMEs across the globe. To do this we utilize the methodology of data envelopment analysis and the Malmquist total factor productivity index.

\section{Methodology}

The DEA model adopted for the study is the strictly output-oriented (Mohamad \& Said, 2010a) with zero input slacks,

maximize $\Omega_{0}$

subject to

$-X_{0 i}+\sum_{k=1}^{s} X_{k i} \lambda_{k}=0, \quad i=1,2, \ldots n$

$-\Omega_{0} Y_{0 j}+\sum_{k=1}^{S} Y_{k j} \lambda_{k} \geq 0, j=1,2, \ldots, m$

$\lambda_{k} \geq 0, k=1,2, \ldots, S$

$\Omega_{0}$ unconstrained,

where $X_{k i}$ and $Y_{k j}$ are observed values of inputs and outputs, $i=1,2, \ldots, n$ and $j=1,2, . ., m$, for each of $k=1,2, . ., S$ decision making units (DMUs) and the $X_{0 i}$ and $Y_{0 j}$ represent the input and output for $\mathrm{DMU}_{0}$ to be evaluated. The efficiency score, $E_{0}$ is given by

$0 \leq E_{0} \leq \frac{1}{\Omega_{\mathrm{o}}} \leq 1$.

If (i) $\Omega_{0}=1$, and (ii) all slacks are zero, then $\mathrm{DMU}_{0}$ is said to attain full or strong efficiency, that is Pareto Koopman's efficiency. Otherwise, weak efficiency is attained if only condition (i) is satisfied. For an inefficient, $\mathrm{DMU}_{0}$ say, improvement or movement towards efficient frontier can be identified by inspecting the system of equations with slacks $t_{j}^{+}$, for all $j$ such that

$\sum_{k=1}^{s} Y_{k j} \lambda_{k}-t_{j}^{+}=Y_{0 j} \Omega_{0}, \quad j=1,2, \ldots, m$. (5)

The projected output is dictated by its peers (identified from $\lambda_{k} \neq 0$, for all $k$ ) and given by

$Y_{0 j}^{\mathrm{n}}=\sum_{k=1}^{S} Y_{k j} \lambda_{k}=Y_{0 j} \Omega_{0}+t_{j}^{+}, j=1,2, \ldots, m(6)$

which can be achieved by proportional increase of $\left(\Omega_{0^{-}}-1\right)$ in all outputs plus additional amount (termed as slacks movements) of $t_{j}^{+}$in output $Y_{0 j}$ whenever $t_{j}+\neq 0$. Thus $\left(\Omega_{0}-1\right) Y_{0 j}+t_{j}^{+}$is a measure of underachievement of output $Y_{0 j}$ experienced by $\mathrm{DMU}_{0}$.

Model (1)-(3) is the output-oriented model under constant returns to scale, CRS. For evaluation under the
Sci.Technol.Edu.

CIndian Society for Education and Environment (iSee)
"Small and Medium enterprises" http://www.indjst.org
N.H.Mohamad \& F.Said Indian J.Sci.Technol. 
assumptions of variables return to scale, VRS an additional convexity constraint is imposed on $\lambda_{k}$ such that $\sum_{k=1}^{S} \lambda_{k}=1$.

This results in the formation of a convex hull of intersecting planes which envelope the data points more tightly than the CRS conical hull and thus provides technical efficiency scores which are greater than or equal to those obtained under the assumptions of CRS. The difference in technical efficiency scores under the two assumptions of returns to scale is mainly attributable to scale efficiency. Thus, scale efficiency, SE can be viewed as the extent to which a DMU can take advantage of return to scale by altering its size towards optimal size identified as the region in which there are CRS in the relationship between outputs and inputs and is computed as $S E_{0}=\frac{E_{0}^{\text {GTS }}}{E_{0}^{\text {FTs }}} \leq 1$.

\section{Malmquist productivity index, MPI}

In order to further study changes that occurred in technical efficiency and technological practices in two different time periods $t$ and $t+1$, we utilized the outputbased MPI of total factor productivity, TFP as given by Mohamad \& Said (2010b),

$$
\begin{aligned}
& M_{k}\left(X_{k}^{(t+1)}, Y_{k}^{(t+1)}, X_{k}^{(t)}, Y_{k}^{(t)}\right)= \\
& -\left\{\left(\frac{D_{k}^{(t)}\left(X_{k}^{(t+1)} Y_{k}^{(t+1)}\right)}{L_{k}^{(t)}\left(X_{k}^{(t)}, Y_{k}^{(t)}\right)}\right)\left(\frac{D_{k}^{(t+1)}\left(X_{k}^{(t+1)}, r_{k}^{(t+1)}\right)}{D_{k}^{(t+1)}\left(X_{k}^{(t)}, Y_{k}^{(t)}\right)}\right)\right\}^{1 / 2} \text { (8) } \\
& \quad \text { where } D_{k}^{(t)}\left(X_{k}^{(t+1)}, Y_{k}^{(t+1)}\right) \text { is the output distance }
\end{aligned}
$$

function for $\mathrm{DMU}_{k}$ with respect to two different time periods under the assumptions of CRS. In other words, if there exist frontier shift (or technological change) in time $t+1$,

$$
D_{k}^{(t)}\left(X_{k}^{(t+1)}, Y_{k}^{(t+1)}\right)=\text { efficiency of conversion of }
$$

inputs in period $(t+1)$ to outputs in period $(t+1)$

$\neq D_{k}^{(t)}\left(X_{k}^{(t)}, Y_{k}^{(t)}\right)$.

relative to technology period $t$

MPI, as given by (8) is thus a geometric mean of the productivity changes between two time periods. A value of $M_{k}>1$ indicates positive TFP growth or gain, $M_{k}<1$ indicates TFP decline or loss, and $M_{k}=1$ indicates stagnation or no change in TFP for $\mathrm{DMU}_{k}$ from time period $t$ to $t+1$.

The MPI can be decomposed into technical efficiency change, TEC (or catching-up effect) and technological change resulting from shifts in the production frontier, $F S$ (or innovation) such that

$M_{k}()=.(T E C)_{k \cdot}(F S)_{k}$ where $T E C_{k}=\frac{D_{k}^{(t+1)}\left(X_{k}^{(t+1)}, Y_{K}^{(t+1)}\right)}{D_{k}^{(t)}\left(X_{k}^{(t)}, Y_{k}^{(t)}\right)}$

and

$$
F S_{k}=\left\{\left(\frac{D_{k}^{(t)}\left(X_{k}^{(t+1)}, Y_{k}^{(t+1)}\right)}{D_{k}^{(t+1)}\left(X_{k}^{(t+1)} Y_{k}^{(t+1)}\right)}\right)\left(\frac{D_{k}^{(t)}\left(X_{k}^{(t)}, Y_{k}^{(t)}\right)}{D_{k}^{(t+1)}\left(E_{k}^{(t+1)} Y_{k}^{(t+1)}\right)}\right)\right\}^{1 / 2}
$$

Fare et al.(1994) further decomposed TEC (relative to CRS frontier) into pure technical efficiency change, PTEC component (relative to VRS frontier) and a residual scale efficiency change, SEC component which captures changes in the deviation between the VRS and CRS technology. Thus the complete decomposition for $\mathrm{DMU}_{\mathrm{k}}$ becomes

$M_{k}()=.(P T E C)_{k \cdot}(S E C)_{k \cdot}(F S)_{k}, k=1,2, \ldots, K .(12)$

Empirical implementation

\section{Data source}

The data utilized for the study are annual time-series data for 42 selected nations covering the period of 20042008. These comprise 29 members of European Union and 13 Asia Pacific Economies. Two measures of output, sales revenue which proxies the physical performance and return on investments which proxies the accounting performance are used. Total number of workers and investment in tangible goods (or capital formation or asset) which is taken as proxy for capital constitute the two measures of input.

For comparative purposes we group the 42 nations into three groups, the developed economies comprises of 20 nations viz. Austria, Belgium, Denmark, Finland, France, Germany, Greece, Ireland, Italy, Luxembourg, Netherlands, Norway, Portugal, Spain, Sweden, United Kingdom, Australia, Canada, New Zealand and Japan, economies in transition comprises 13 nations viz. Bulgaria, Cyprus, Czech Republic, Estonia, Hungary, Latvia, Lithuania, Malta, Poland, Romania, Slovakia, Slovania and Albania, and the developing economies comprises 9 nations viz. China, Hong Kong, Indonesia, Korea, Malaysia, Pakistan, Singapore, Thailand and Turkey. The mean basic statistics for the parameters is given in table 1. Mathematically speaking, the indicators are

X1: total employment,

$\mathrm{X} 2$ : investment in tangible goods (or capital formation), in million EURO,

$Y 1$ : sales revenue, in million EURO, and

Y2: return on investment.

Next, all indicators (including inputs) are normalized on a scale of $[1,100]$ such that

$$
X_{\text {nor }}=\frac{99\left(x_{a t t}-X_{\min }\right)}{X_{\max }-x_{\min }}+1
$$

where $X_{\text {nor }}$ is the value of the normalized indicator, $X_{a c t}$ is the actual value of the indicator, $X_{\max }$ is the maximum value of the indicator, $X_{\min }$ is the minimum value of the indicator.
N.H.Mohamad \& F.Said Indian J.Sci.Technol. 
Table 1. Basic descriptive statistics 2004-2008

\begin{tabular}{|l|l|l|l|l|}
\hline Indicators & Mean & Maximum & Minimum & $\begin{array}{l}\text { Std. } \\
\text { deviation }\end{array}$ \\
\hline $\begin{array}{l}\text { 2008 } \\
\text { X1:Employment }\end{array}$ & 8782782 & 75888616 & 88499 & 16949871 \\
X2: (Mil EURO) & 104809 & 2885891 & 272 & 441644 \\
Y1: (Mil EURO) & 406946 & 3654545 & 4172 & 657618 \\
Y2: (Ratio) & 9.703 & 33.559 & 1.232 & 6.447 \\
\hline 2007 & & & & \\
X1:Employment & 8711181 & 82693604 & 90128 & 16991800 \\
X2: (Mil EURO) & 88070 & 2316171 & 280 & 354252 \\
Y1: (Mil EURO) & 368070 & 2662167 & 4982 & 539194 \\
Y2: (Ratio) & 10.004 & 33.562 & 1.271 & 6.301 \\
\hline 2006 & & & & \\
X1:Employment & 8651345 & 87035328 & 87523 & 17179857 \\
X2: (Mil EURO) & 76230 & 1917709 & 257 & 293430 \\
Y1: (Mil EURO) & 340326 & 2185868 & 3958 & 481915 \\
Y2: (Ratio) & 9.827 & 33.562 & 1.140 & 6.462 \\
\hline 2005 & & & & \\
X1:Employment & 8521180 & 76530275 & 85739 & 16845307 \\
X2: (Mil EURO) & 71376 & 1833937 & 240 & 280555 \\
Y1: (Mil EURO) & 295349 & 1918824 & 3698 & 429082 \\
Y2: (Ratio) & 8.971 & 18.907 & 1.046 & 4.886 \\
\hline 2004 & & & & \\
X1:Employment & 8673701 & 79256100 & 85608 & 17805762 \\
X2: (Mil EURO) & 66852 & 1750165 & 222 & 267941 \\
Y1: (Mil EURO) & 281035 & 1867936 & 3698 & 414200 \\
Y2: (Ratio) & 9.509 & 18.325 & 1.067 & 5.111 \\
\hline
\end{tabular}

This transformation ensures that $X_{\text {nor }} \in[1,100]$, and is synonymous with United Nation Human Development Index. We then solve the DEA outputoriented model under the assumptions of CRS and VRS using LINDO Version 6.0 software for each year. Results for the mean efficiency scores and returns to scale are summarized in table 2.

Technical and scale efficiency

Out of the 42 economies, only two (Luxembourg and Albania) obtain a scale efficiency score of 100 percent, implying that it is technically efficient in all years under evaluation and are operating on the frontier at the most productive scale size, mpss. Forty-two or $95.24 \%$ are technically inefficient implying that, in general, more than 95 percent of the SMEs were operating inefficiently and they need to increase their output (or reduce their inputs) to become efficient. The average PTE score was $56.90 \%$ during 2004-2008. This finding suggests that if these SMEs were operating efficiently, they could have produced $43.10 \%$ more output. Despite the low technical efficiencies, more than $38 \%$ of the DMUs obtained scale efficiency of above $90.0 \%$. On average the scores for developing economies are higher than the economies in transition which are higher than the developing economies (Table 1).

\section{Returns to scale}

Apart from the inefficiency that could arise in the conversion process, another reason for the inefficiency of the inefficient units can be attributed to the scale of operations. DMUs that do not operate at the most efficient (or productive) scale size cannot be fully efficient. The inefficiency may arise because it is operating under decreasing returns to scale, drs or increasing returns to scale, irs. Whether a DMU is operating under irs or drs can be determined by observing its TE and PTE scores, such that

- if $T E=P T E$, CRS prevails

- if $T E \neq P T E$, then

Table 2. Mean efficiency scores 2004-2008

\begin{tabular}{|c|c|c|c|c|}
\hline Country & $T E$ & PTE & $S E$ & rts \\
\hline Austria & 0.40621 & 0.42926 & 0.94683 & irs \\
\hline Belgium & 0.57315 & 0.59060 & 0.97517 & irs \\
\hline Bulgaria & 0.21108 & 0.28827 & 0.72434 & irs \\
\hline Cyprus & 0.71326 & 0.78780 & 0.89947 & irs \\
\hline Czech Republic & 0.61131 & 0.62220 & 0.98165 & drs \\
\hline Denmark & 0.40012 & 0.42808 & 0.93608 & irs \\
\hline Estonia & 0.50036 & 0.58758 & 0.85791 & irs \\
\hline Finland & 0.66334 & 0.70176 & 0.95361 & irs \\
\hline France & 0.57559 & 0.85716 & 0.66502 & drs \\
\hline Germany & 0.78277 & 0.98261 & 0.79556 & drs \\
\hline Greece & 0.46141 & 0.46543 & 0.99048 & drs \\
\hline Hungary & 0.33026 & 0.35371 & 0.93809 & irs \\
\hline Ireland & 0.71915 & 0.77633 & 0.93098 & irs \\
\hline Italy & 0.85613 & 1.00000 & 0.85613 & drs \\
\hline Latvia & 0.23182 & 0.34434 & 0.68653 & irs \\
\hline Lithuania & 0.25339 & 0.37432 & 0.69293 & irs \\
\hline Luxembourg & 1.00000 & 1.00000 & 1.00000 & mpss \\
\hline Malta & 0.85648 & 1.00000 & 0.85648 & irs \\
\hline Netherlands & 0.67576 & 0.68232 & 0.99126 & irs \\
\hline Norway & 0.48514 & 0.62105 & 0.83263 & irs \\
\hline Poland & 0.58800 & 0.59672 & 0.98555 & irs \\
\hline Portugal & 0.34502 & 0.35759 & 0.96856 & irs \\
\hline Romania & 0.17271 & 0.20426 & 0.85364 & irs \\
\hline Slovakia & 0.34700 & 0.41558 & 0.85113 & irs \\
\hline Slovania & 0.36472 & 0.43863 & 0.84566 & irs \\
\hline Spain & 0.56650 & 0.69468 & 0.81497 & drs \\
\hline Sweden & 0.84612 & 0.85741 & 0.98244 & irs \\
\hline U. Kingdom & 0.75293 & 0.90039 & 0.83246 & drs \\
\hline Albania & 1.00000 & 1.00000 & 1.00000 & mpss \\
\hline Australia & 0.27286 & 0.39823 & 0.66348 & drs \\
\hline Canada & 0.74993 & 0.96530 & 0.77143 & drs \\
\hline New Zealand & 0.21701 & 0.27709 & 0.79218 & irs \\
\hline China & 0.12225 & 1.00000 & 0.12225 & drs \\
\hline Hong Kong & 0.28033 & 0.38096 & 0.78179 & drs \\
\hline Indonesia & 0.17679 & 0.19746 & 0.89141 & drs \\
\hline Japan & 0.65292 & 0.69661 & 0.92388 & drs \\
\hline Korea & 0.15736 & 0.23125 & 0.68113 & drs \\
\hline Malaysia & 0.17418 & 0.23879 & 0.72494 & irs \\
\hline Pakistan & 0.13341 & 0.30217 & 0.77073 & irs \\
\hline Singapore & 0.19560 & 0.22526 & 0.87236 & irs \\
\hline Thailand & 0.15496 & 0.16723 & 0.91880 & irs \\
\hline Turkey & 0.45451 & 0.46045 & 0.98617 & irs \\
\hline Average & 0.47932 & 0.56902 & 0.84634 & \\
\hline Std. Deviation & 0.25408 & 0.27269 & 0.15442 & \\
\hline Maximum & 1.00000 & 1.00000 & 1.00000 & \\
\hline Minimum & 0.12225 & 0.16723 & 0.12225 & \\
\hline Dev. economies & 0.60012 & 0.68410 & 0.88116 & \\
\hline Econ. in transition & 0.47541 & 0.53949 & 0.85949 & \\
\hline Developing econ. & 0.21650 & 0.35595 & 0.74995 & \\
\hline
\end{tabular}

Note: $d r s$ and irs refer to decreasing and increasing returns to scale respectively, while mpss refers to most productive scale size.
Sci.Technol.Edu.

Clndian Society for Education and Environment (iSee)
"Small and Medium enterprises" http://www.indjst.org
N.H.Mohamad \& F.Said Indian J.Sci.Technol. 
$\left\{\begin{array}{l}\sum_{j=1}^{K} \lambda_{j}<1 \rightarrow i r s, \\ \sum_{j=1}^{K} \lambda_{j}>1 \rightarrow d r s .\end{array}\right.$

The last column in Table 2 records the returns to scale based on the most frequent observed during the years under consideration. As mentioned earlier, SMEs from two economies (4.76\%), Luxembourg and Albania appeared to be operating at their mpss. SMEs from fifteen economies $(35.71 \%)$ exhibited $d r s$. These SMEs on average should scale down their scale of operation if they were to operate on the frontier. The remainder SMEs from twenty-five economies (59.52\%) exhibited irs. These SMEs on average should expand their scale of operation in order to become scale efficient. The average scale efficiency score in the sample for the period 2004-2008 was 47.93 percent, ranging from a minimum of 12.23 percent to a maximum of 100 percent. It is worth noting that China obtained the lowest technical efficiency score of $12.23 \%$, but it scored $100 \%$ under pure technical efficiency. Location wise, it is on the VRS frontier with decreasing return to scale but furthest from the CRS frontier. Malta, on the other hand is on the VRS frontier with increasing return to scale.

Malmquist productivity change

Table 3 presents a summary of the annual geometric means of the Malmquist productivity index and its components. As can be observed, on average, the TFP for SMEs in all nations showed a decrease of 2.38 percent per annum, ranging from the lowest of -11.83 percent (Denmark) to the highest of 12.22 percent (Sweden). This decrease is largely due to technical efficiency change, TEC or adaptation (of $-3.47 \%$ per year) rather than frontier shift, $F S$ which is synonym with innovation or adoption. The technological change on average improved by a small amount of $1.30 \%$ per annum while technical efficiency regressed by 3.47 percent per annum. Hence catching up (i.e diffusion of technology) is a problem facing SMEs in most countries due to both PTEC and SEC $(-0.71 \%$ and $-2.78 \%$ respectively). Only six (14.29\%) countries viz. France, Ireland, Sweden, Albania, China and Turkey, have their SMEs exhibiting improvement in all components.

Twelve (28.57\%) countries have their SMEs showing positive TFP growth while another thirty (71.43\%) countries recorded negative growth. The highest TFP growth comes from SMEs in Sweden $(12.22 \%$ per annum) while the lowest is from SMEs in Denmark ($12.31 \%$ per annum).

\section{Technological change (frontier shift)}

SMEs in thirty countries experienced technological progress since the $F S_{k}$ index attains a value greater than one. The average score was 1.013 , indicating a $1.3 \%$ technological progress per annum. The highest technological progress of $12.03 \%$ per annum was
Vol. 5 No. 5 (May 2012)

ISSN: 0974- 6846

Table 3. Mean Malmquist productivity index change 2004-2008

\begin{tabular}{|c|c|c|c|c|c|}
\hline Country & $M_{k}()$. & $F S_{k}$ & $T E C_{k}$ & PTE $C_{k}$ & $S E C_{k}$ \\
\hline Austria & 0.965 & 1.120 & 0.862 & 0.975 & 0.884 \\
\hline Belgium & 0.918 & 1.107 & 0.829 & 0.828 & 1.002 \\
\hline Bulgaria & 0.926 & 0.988 & 0.938 & 0.915 & 1.025 \\
\hline Cyprus & 0.981 & 0.957 & 1.026 & 0.973 & 1.055 \\
\hline Czech Rep & 1.009 & 1.039 & 0.970 & 0.973 & 0.993 \\
\hline Denmark & 0.882 & 1.005 & 0.877 & 0.893 & 0.982 \\
\hline Estonia & 0.982 & 0.967 & 1.015 & 1.031 & 0.985 \\
\hline Finland & 0.944 & 1.014 & 0.930 & 0.930 & 1.001 \\
\hline France & 1.014 & 1.001 & 1.013 & 0.979 & 1.034 \\
\hline Germany & 0.976 & 1.037 & 0.945 & 1.097 & 0.861 \\
\hline Greece & 1.009 & 0.958 & 1.053 & 0.917 & 1.149 \\
\hline Hungary & 1.004 & 0.992 & 1.012 & 0.995 & 1.017 \\
\hline Ireland & 1.043 & 1.007 & 1.036 & 1.026 & 1.009 \\
\hline Italy & 0.981 & 1.035 & 0.948 & 1.000 & 0.948 \\
\hline Latvia & 1.005 & 1.050 & 0.957 & 0.916 & 1.045 \\
\hline Lithuania & 0.979 & 1.006 & 0.973 & 0.965 & 1.008 \\
\hline Luxembourg & 0.898 & 0.898 & 1.000 & 1.000 & 1.000 \\
\hline Malta & 0.971 & 0.918 & 1.057 & 1.000 & 1.057 \\
\hline Netherlands & 0.986 & 0.986 & 1.000 & 1.001 & 0.999 \\
\hline Norway & 1.016 & 1.069 & 0.951 & 1.064 & 0.893 \\
\hline Poland & 1.010 & 0.988 & 1.023 & 1.027 & 0.996 \\
\hline Portugal & 0.961 & 0.988 & 0.973 & 0.968 & 1.005 \\
\hline Romania & 0.941 & 0.923 & 1.018 & 0.980 & 1.039 \\
\hline Slovakia & 0.907 & 0.972 & 0.933 & 1.006 & 0.928 \\
\hline Slovania & 0.994 & 1.005 & 0.989 & 1.057 & 0.935 \\
\hline Spain & 0.964 & 1.028 & 0.937 & 1.006 & 0.932 \\
\hline Sweden & 1.122 & 1.012 & 1.109 & 1.138 & 0.975 \\
\hline U. Kingdom & 0.978 & 1.040 & 0.940 & 0.989 & 0.951 \\
\hline Albania & 1.002 & 1.002 & 1.000 & 1.000 & 1.000 \\
\hline Australia & 0.921 & 1.058 & 0.870 & 1.014 & 0.858 \\
\hline Canada & 0.951 & 1.069 & 0.890 & 0.985 & 0.904 \\
\hline New Zealand & 0.996 & 1.061 & 0.939 & 0.957 & 0.981 \\
\hline China & 1.064 & 1.002 & 1.062 & 1.000 & 1.062 \\
\hline Hong Kong & 0.943 & 1.006 & 0.938 & 0.972 & 0.962 \\
\hline Indonesia & 0.962 & 1.021 & 0.942 & 0.987 & 0.954 \\
\hline Japan & 0.974 & 1.030 & 0.946 & 0.936 & 1.010 \\
\hline Korea & 0.981 & 1.037 & 0.946 & 1.010 & 0.936 \\
\hline Malaysia & 0.938 & 1.032 & 0.909 & 1.086 & 0.837 \\
\hline Pakistan & 0.989 & 1.008 & 0.981 & 1.011 & 0.970 \\
\hline Singapore & 0.905 & 1.050 & 0.861 & 1.011 & 0.852 \\
\hline Thailand & 0.924 & 1.024 & 0.903 & 1.055 & 0.856 \\
\hline Turkey & 1.084 & 1.041 & 1.041 & 1.025 & 1.016 \\
\hline Average & 0.976 & 1.013 & 0.965 & 0.993 & 0.976 \\
\hline Std. & 0.049 & 0.045 & 0.062 & 0.056 & 0.068 \\
\hline Deviation & 1.122 & 1.120 & 1.109 & 1.138 & 1.149 \\
\hline Maximum & 0.882 & 0.898 & 0.829 & 0.828 & 0.837 \\
\hline Minimum & & & & & \\
\hline Dev. & 0.974 & 1.026 & 0.952 & 0.985 & 0.974 \\
\hline economies & 0.978 & 0.985 & 0.993 & 0.988 & 1.006 \\
\hline Econ. in & 0.977 & 1.025 & 0.954 & 1.017 & 0.938 \\
\hline transition & & & & & \\
\hline $\begin{array}{l}\text { Developing } \\
\text { econ. }\end{array}$ & & & & & \\
\hline
\end{tabular}

Note: All Malmquist index averages are geometric means.

achieved by SMEs in Austria while the lowest innovative improvement of $-10.15 \%$ per annum was recorded by SMEs in Luxembourg which was $100 \%$ technically efficient during the period 2004 - 2008. On group comparison, the developed economies showed a slightly 
better improvement than the developed economies (2.29\% as compared to $2.46 \%$ per annum). Economies in transition lagged behind with a negative growth of $-1.49 \%$ per annum.

\section{Technical efficiency change (catching up effect)}

Only twelve (28.57\%) showed improvement in technical efficiency with SMEs in Sweden attaining the highest score of 1.1093 (catching up rate of $10.93 \%$ per annum). Twenty-eight (66.67\%) appeared to be lagging behind with SMEs in Belgium recording the lowest score of 0.8292 (a decline of $-17.08 \%$ per annum). On average, the group was found to be staggering behind at $-3.47 \%$ per annum. This indicates that technical efficiency is not improving in line with technological progress. In other words, the gap to the efficient frontier is widening. SMEs from Luxembourg and Albania, which were $100 \%$ technical efficient obtained a score of unity, meaning they remained unchanged. All three groups of economies exhibited negative growth (Table 3.)

Pure technical efficiency change

As mentioned earlier, TEC is the product of PTEC and $S E C$. Seventeen (40.48\%) indicated increase in pure technical efficiency with SMEs from Sweden taking the lead with improvement of $13.79 \%$ per annum. Twenty $(47.62 \%)$ indicated a decrease with SMES from Belgium retaining the lowest score of negative growth at $-17.22 \%$ per annum. The remainder five (11.90\%) showed no change during the period under consideration as indicated by their PTEC score of unity. Only the developing economies indicated a small increase of $1.74 \%$ per annum.

\section{Scale efficiency change}

Sixteen (38.10\%) of the DMUs contribute positively to the productivity change since their scores exceed one. SMEs in Greece recorded the highest score of 1.14891 (a change of $14.89 \%$ per annum), while SMEs in Malaysia recorded the lowest score of 0.83728 (a change of $16.28 \%$ per annum). The average score for the group is 0.97649 (a decrease of $2.35 \%$ per annum). Economies in transition indicated a small positive change of $0.64 \%$ per annum. The other two groups exhibited on average a decrease of about $-2.68 \%$ and $-6.16 \%$ per annum respectively.

\section{Observations}

From the above discussions, we can highlight a few observations.

- The Malmquist TFP index for global SMEs from the countries under evaluation indicated only a decrease of $-2.38 \%$ per annum. All the three groups exhibited negative total productivity growth.

- The TFP growth is largely due to innovation (a small positive shift in the frontier) rather than technical efficiency change (catching up effect). Two of the groups, the developed and developing economies, exhibited a positive frontier shift of about $2.5 \%$ per annum respectively.
- A decrease in TEC is attributable to both decrease in PTEC and SEC. All the three groups attained on average negative PTEC.

- SMEs in Sweden on average achieved the highest TFP growth with all components, except $S E C$ indicating positive changes.

- SMEs in Denmark on average recorded the lowest TFP growth with negative scores in three components despite encouraging improvement in $F S$ score. The low TEC was due to the low PTEC and SEC.

\section{Policy implication}

The analysis provides some interesting policy implications. The study found that SMEs in two countries viz. Luxembourg and Albania were operating at mpss. This should be sustained as long as possible since they were classified as 100 percent technically efficient. Fifteen (or $35.71 \%$ ) of the economies were found to exhibit $d r s$, suggesting an over-utilization of input resources, both labour and capital. Thus scaling down their scale of operation is an appropriate action for these sub-industries if they were to be on the efficient frontier. Another $59.52 \%$ of the DMUs were operating under irs. This suggests under-utilization of input resources, both in terms of quality and quantity, and provides potential for expansion. Thus expanding their scale of operation by injecting further investments in existing SMES and/or new investment in new establishments seems the right move forward.

On the technology side, the adoption of new technology, although positive in two of the economies, it is relatively slow but encouraging at $2.5 \%$ per annum. The catching-up effect which indicates the gap to the efficient frontier, on the other hand is widening. Therefore, it seems that the choice of technology adopted is not in line with the skills available. Training should be provided by relevant parties such as government and employers for workers to acquire new and higher skills appropriate for the technology before adoption is made. Further, workers should be made more flexible and easily adaptable to new technology. Movements within subindustries should be made easy, say from an establishment exhibiting $d r s$ to an establishment exhibiting irs.

\section{Conclusions}

In this study, we have estimated the Malmquist TFP index and its decompositions using the output-oriented DEA distance functions for SMEs in 42 economies for the period 2004-2008. The findings indicate that TFP did not exhibit a positive growth despite an encouraging frontier shift or innovative improvement of $1.30 \%$ per annum. This is due to a decline in the catching up effect or TEC of 3.47 percent per annum which is further attributable to decrease in both PTEC and SEC. Only SMEs in two countries were found to be operating efficiently (exhibiting mpss) while forty exhibited variable returns to scale, indicating the needs for operation adjustments. The findings suggest that SMEs from fifteen and twenty-five
Sci.Technol.Edu.

CIndian Society for Education and Environment (iSee)
"Small and Medium enterprises" http://www.indjst.org
N.H.Mohamad \& F.Said Indian J.Sci.Technol. 
countries should scale down and expand their scale of operations respectively if they were to be operating on the efficient frontier.

The study is not without limitations. DEA is nonstochastic and does not capture random noise, thereby may have over-estimated the magnitude of inefficiencies. The data utilized in the study are aggregated data and not firm level data. This is because firm level data is not easily accessible. The study also assumes that all SMES under evaluation are fairly homogenous, utilizing similar set of inputs to produce identical outputs. This can only be achieved if we are evaluating a group of firms operating similar business activities such as banking or financial institutions, hospitals and others. The methodology can be revised, expanded and applied to other public and private organizations.

\section{References}

1. Afonso A and Fernandes S (2006) Measuring local government spending efficiency: Evidence from the Lisbon region. Regional Studies. 40(1),39-53.

2. Ardabili JS, Aghayi N and Monzali A (2007) New efficiency using undesirable factors of data envelopment analysis. Adv. Modeling \& Optimization. 9(2), 249-255.

3. Azar A, Olfat L, Khosravani F and Jalali R (2011) A BSC method for supplier selection strategy using TOPSIS and VIKOR. A case study of part maker industry. Manage. Sci. Lett. 1(4),559-568.

4. Banker RD, Chang $\mathrm{H}$, Janakiraman $\mathrm{SN}$ and Konstans $\mathrm{C}$ (2004) A balanced scorecard analysis of performance metrics. Euro.J. Operational Res. 154(2), 423-436.

5. Barkema HG, Baum JAC and Mannix EA (2002) Management challenges in a new time. Acad. Manage. J. 44(5), 916-930.

6. Barros CP and Dieke PUC (2008) Technical efficiency of African hotels. Int. J. Hospitality Manage. 27(3), 438-447.

7. Bhandari AK and Maiti P (2007) Efficiency of Indian manufacturing firms: textile industry as a case study. Int.J. Bus. \& Econ. 6(1), 71-88.

8. Boame AK (2004) The technical efficiency of Canadian urban transit systems. Transportation Res. Part E, 40(5), 401-416.

9. Chakraborty T, Ghosh T and Dan PK (2011) Application of analytic hierarchy process and heuristic algorithm in solving vendor selection problem. Bus. Intelligence J. 4(1), 167-177.

10. Chelliah S, Sulaiman M and Yusoff YM (2010) Internationalization and performance: small and medium enterprises (SMEs) in Malaysia, Int. J. Bus. \& Manage. 56(6), 27-37.

11. Chen T and Lu LY (2006) Innovation and the operational performance of IC design industry in Taiwan: a data envelopment analysis. Conference paper presented at Intenational Conference on Management of Technology (IAMOT2006), Beijing, China. ISBN: 0-9712964-8.0, 2006.

12. Coli M, Nissi E and Rapposelli A (2007) Efficiency evaluation by means of data envelopment analysis: strengths and weaknesses. In: Methods, models and information technologfies for decision support systems. First Part: Methodologies. D'Ambra L, Rostirolla P \& Squillante M (Eds.), FranceAngeli, Milano.

13. Emrouznejad A, Barnett RP and Tavares GT (2008) Evaluation of research in efficiency and productivity: A
Vol. 5 No. 5 (May 2012)

ISSN: 0974- 6846

survey analysis of the first 30 years of scholarly literature in DEA. Socio-Economic Planning Sci. 42(3),151-157.

14. Fare R, Grosskoph S, Norris M and Zhang Z (1994) Productivity growth, technical progress and efficiency change in industrialised countries. Am. Econ. Rev. 84(1), 63-83.

15. Hasanov S and Nomman AM (2011) Agricultural efficiency under resource scarcity in Uzbekistan: A data envelopment analysis. Bus. \& Econ. Horizon. 4(1), 81-87.

16. Hossain MZ and Al-Amri KS (2010) Use of Cobb_Douglas production model on some selected manufacturing industries in Oman. Edu., Bus. \& Soc. Contemporary Middle Eastern Issues. 3(2), 78-85.

17. Kao $\mathrm{C}$ and Hung $\mathrm{H}$ (2008) Efficiency analysis of university departments: An empirical study. OMEGA, The Int. J. Manage. Sci. 36(4),653-666.

18. Laforet $S$ and Tann $J(2006)$ Innovative characteristics of small manufacturing firms. J. Small \& Enterprise Dev. 13(3), 363-390.

19. Laine J, Finne-Soveri UH, Bjorkgren M, Linna M, Noro A and Hakkinen $U$ (2005) The association between quality of care and technical efficiency in long-term care, Int. J. Quality Health Care. 17 (3), 259-267.

20. Mohamad NH and Said F (2010a) Measuring the performance of 100 largest listed companies in Malaysia. Afr. J. Bus. Manage. 4(13), 3178-3190.

21. Mohamad NH and Said F (2010b) Decomposing productivity growth in Malaysian food manufacturing industry. Afr. J. Bus.Manage. 4 (17), 3522-3529.

22. Mohamad NH and Said F (2011a) Efficiency and innovation in selected Malaysian government-linked companies for the period 2003-2008. Afr. J. Bus. Manage. 5(25),10259-10270.

23. Mohamad NH and Said F (2011b) Comparing macroeconomic performance of OIC member countries, International J. Econ. \& Manage. Sci. 1(3):90-104

24. Mostafa M (2007) Benchmarking top Arab banks' efficiency through efficient frontier analysis.Ind. Manage. \& Data Systems. 107(6), 802-823.

25. Radam A, Abu M and Abdullah AM (2008) Technical efficiency of small and medium enterprises in Malaysia: a stochastic frontier production model. Int. J. Econ. \& Manage. 2(2), 395-408.

26. Shackleton C (2007) Developing key performance indicator for corporate communication in the information technology industry. Unpublished Master Thesis, Faculty of Economics and Management Sciences, University of Pretoria.

27. Shazali AM, Alias R and Rossazana AR (2004) Technical efficiency on furniture industry in Malaysia, The Asian Economic Rev. J. Indian Institute of Econ. 46(2), 377-384.

28. Tavares G (2002) A bibliography of data envelopment analysis (1978-2001). Rutcor Res.Report, RRR 01-02, January 2002.

29. Wanke PF, Barbastefano RG and Hijjar MF (2011) Determinants of efficiency at major Brazilian port terminals. Transport Rev. 31(5), 653-677.

30. Yahya AZ, Othman MS, Othman AS, Rahman IA and Moen JA (2011) Process innovation: a study of Malaysian small medium enterprises (SMEs). World J. Manage. 3(1),146156.

31. Yang $\mathrm{J}$ (2006) The efficiency of SMEs in the global market: Measuring the Korean performance, J.Policy Modeling. 28(8), 861-876.
Sci.Technol.Edu.

(CIndian Society for Education and Environment (iSee)
"Small and Medium enterprises" http://www.indjst.org
N.H.Mohamad \& F.Said Indian J.Sci.Technol. 